\title{
Estimating the risk-return profile of new venture investments using a risk-neutral framework and 'thick' models
}

July 6, 2012

\begin{abstract}
This study proposes cascade neural networks to estimate the model parameters of the Cox-Ross-Rubinstein risk-neutral approach, which, in turn, explain the risk-return profile of firms at venture capital and initial public offering financing rounds. Combining the two methods provides better estimation accuracy than risk-adjusted valuation approaches, conventional neural networks, and linear benchmark models. The findings are persistent across in-sample and out-of-sample tests using 3,926 venture capital and 1,360 US initial public offering financing rounds between January, 1989 and December 2008. More accurate estimates of the riskreturn profile are due to less heterogeneous risk-free rates of return from the risk-neutral framework. Cascade neural networks nest both the linear and nonlinear functional estimation form in addition to taking account of variable interaction effects. Better estimation accuracy of the risk-return profile is desirable for investors so they can make a more informed judgement before committing capital at different stages of development and various financing rounds.
\end{abstract}

Keywords: Risk-neutral framework, risk-return profile, financing rounds, neural networks

JEL classification: C13; C31; C45; C53; G17; G11; G24 


\section{Introduction}

This study proposes cascade neural networks to estimate the model parameters of the Cox-Ross-Rubinstein (1979) risk-neutral approach, which, in turn, explain the risk-return profile of firms at venture capital and initial public offering financing rounds. Cascade neural networks nest both the linear and nonlinear functional estimation form. In this study, I combine the risk-neutral approach with the cascade neural network technique and compare the estimation accuracy with the risk-adjusted valuation approaches, conventional neural networks, and linear benchmark models.

Estimating the risk-return profile of privately held firms at various stages of development and financing rounds is difficult. The use of traditional riskadjusted valuation techniques is problematic because conventional asset pricing models such as the Capital Asset Pricing Model (CAPM) rely on stock market trading data. However, privately held firms do not have a stock market listing. Also, the risk-return profile of new ventures changes as they advance through different stages of development and various financing rounds. Privately owned firms have no obligation to disclose information on the amount of capital injected and their valuation at financing rounds. Published estimates of risk-adjusted rates of return are rare. Ruhnka and Young $(1987,1991)$ and Wetzel (1981) are among the few studies to publish estimates of the risk-adjusted rates of return for various stages of development.

To overcome the limitations associated with conventional risk-adjusted valuation approaches, the literature documents alternative ways of estimating the risk-return profile of venture capital and initial public offering financing rounds. One strand of the literature focuses on staged financing. Staged financing is a prominent feature as new venture firms advance through different development stages. In staged financing, investors have an option, but not an obligation to commit capital at consecutive financing rounds. ${ }^{1}$ Having option-like features enables investors to share risk with firms, minimise agency costs and information asymmetry, while retaining some control over the firm. These option-like features enable this study to estimate the risk-return profile with the help of the Cox-Ross-Rubinstein risk-neutral framework. This approach has several benefits. The risk-free rate of return is less subjective than estimates of the riskadjusted rates of return for different stages of development and various financing rounds. ${ }^{2}$ Therefore, the risk-neutral approach should have lower estimation errors because the risk-free rates of return are less heterogeneous compared to 
the risk-adjusted rates of return. These assertions are consistent with findings in the literature; for example, Seppä and Laamanen (2001). In their study, the estimation accuracy of the risk-neutral approach is, in general, better when compared to the risk-adjusted approach. ${ }^{3}$

Ideally, the features likely to impact on the model parameters of the CoxRoss-Rubinstein approach should be based on variables available to investors at financing rounds. For example, Seppä and Laamanen (2001) use the stages of development, the number of financing rounds prior to the current round, the amount of capital injected, and the length of time between the financing rounds. Casamatta and Haritchabalet (2007) note that the level of investor syndication improves the screening process and thus helps to mitigate information asymmetry about firm value at financing rounds. Accordingly, Admati and Pfleiderer (1994) use the level of syndication to certify firm value and risk. Hanley (1993) uses the partial adjustment in the offer price between the filing of the preliminary and the final prospectus, to explain the mispricing at initial public offering financing rounds. Gompers and Lerner (2000) find a correlation between the valuation of private equity transactions and the performance of the aggregate stock market. Loughran and Ritter (2004), Lowry (2003), and Yung, Çolak and Wei (2008) identify two stylised facts from the IPO literature. Firstly, underpricing and issue volume are highly autocorrelated. Secondly, there is a positive correlation between the two series.

Traditionally, the literature uses multivariate linear regressions to estimate the risk-return profile. These studies rule out the possibility of nonlinearity. No previous study has applied artificial neural networks in the present context despite their widespread appeal as data driven, universal function approximators in option pricing. ${ }^{4}$ For example, Hutchinson, Lo and Poggio (1994) use neural networks to 'learn' the Black-Scholes option pricing formula. In their analysis, artificial neural networks provide more accurate valuation estimates when the underlying asset pricing dynamics are unknown or when the option pricing formula cannot be solved analytically. We also know from the literature that the cascade neural network architecture can potentially provide better estimation accuracy. For example, Malik and Nasereddin (2006) report that cascade neural networks have smaller estimation errors than conventional artificial neural networks when estimating the gross domestic product of an economy.

Neither the application of the Cox-Ross Rubinstein framework nor the use of cascade neural networks is novel. The contribution of the present study lies in the combination of these two methods. This novel approach provides 
better estimation accuracy of the risk-return profile at financing rounds than benchmark models. Better estimation accuracy is desirable for investors so they can make a more informed judgement before committing capital at different financing rounds.

I use the Cox-Ross-Rubinstein approach to estimate the risk-neutral probability of an up-movement in firm value between consecutive financing rounds. It is surprising that the risk-neutral framework has not attracted more attention in the literature despite the benefits of relying on risk-free rates of return. They are less subjective and less heterogeneous than estimates of the risk-adjusted rates of return.

In this paper, I use previously untested cascade neural networks to estimate the Cox-Ross-Rubinstein model parameters. In the cascade architecture, the researcher does not enforce the hidden nodes. They are determined by the data endogenously following the true spirit of neural network learning. Neural learning lets the data decide what the 'true' underlying relationship is between variables. I compare the estimation accuracy of the cascade neural networks to conventional neural networks and linear benchmark models. Linear regression models do not account for nonlinearity and variable interaction effects unless they are specified a priori. In this study, the neural networks leave the functional form unrestricted and let the data determine what the 'true' functional form is. 'Thick' models are neural networks, which rely on different neuron connections, number of neurons, starting values at network initialisation, and trimmed mean estimates. $^{5}$

In contrast to prior studies, I perform out-of-sample tests to assess the riskreturn estimation accuracy of the different approaches using ex ante and ex post values. Seppä and Laamanen (2001) only use in-sample comparisons to assess estimation accuracy. This limited approach could undermine the validity their findings. Therefore, the present study provides a truly acid test on model performance by using unseen data, which are not part of the estimation set.

Moreover, I use a unique US dataset of 3,926 venture capital and 1,360 initial public offerings financing rounds that have obtained a listing on a US stock exchange between January, 1986 and December, 2008. This sample therefore exceeds both the absolute number of observations and the period under investigation in Seppä and Laamanen (2001). ${ }^{6}$ My sample represents 39 industry sectors using the 48-industry classification of Fama and French (1997). ${ }^{7}$ In addition, the present study segments the data into venture capital and initial public offering financing rounds to reflect the different risk-return profile. This allows 
the present analysis to include previously untested variables relating to the partial adjustment of offer prices in Hanley (1993) and the level of syndication in Admati and Pfleiderer (1994).

Generally, my findings show that combining the risk-neutral approach with the cascade neural network methodology provides better estimation accuracy of the risk-return profile than risk-adjusted valuation approaches, conventional neural networks, and linear benchmark models. The findings are persistent across in-sample and out-of sample tests.

\section{The Cox-Ross-Rubinstein model}

I use the Cox-Ross-Rubinstein method and the ex post firm value to derive the risk-return profile at financing rounds. The ex post firm value reflects the post-money valuation and includes the capital injected at each financing round. Firm value $V_{t, s}$ at the beginning of stage $s$ can increase to $V^{u}$ or decrease to $V^{d}$ over one period $(t, T)$. The definition of the up-movement in firm value $u_{s}$ is:

$$
u_{s}=\frac{V_{T, s}^{u}}{V_{T, s}^{d}}
$$

provided that $u_{s}>1$. The down-movement is $d_{s}=1 / u_{s}$ and must satisfy $0<$ $d_{s}<1 . u$ and $d$ allows calculating the implied risk-neutral success probability of an up-movement $p$ for each stage $s$ :

$$
p_{s}=\frac{e^{r_{f, s}(T-t)_{s}}-d_{s}}{u_{s}-d_{s}} \quad 0 \leq p_{s} \leq 1
$$

where $r_{f, s}$ denotes the continuously compounded risk-free Treasury-bill rate. Eq. (2) implies that higher returns have lower risk-neutral probabilities. Firm value at the beginning of stage $s$ is the discounted expectation under the riskneutral probability distribution $\left(p_{s}, 1-p_{s}\right)$ of the firm value in the up or the down states at time $T$ :

$$
V_{t, s}=e^{-r_{f, s}(T-t)_{s}}\left(p_{s} V_{T, s}^{u}+\left(1-p_{s}\right) V_{T, s}^{d}\right)
$$

Discounting is at the risk-free rate of return over the period $(t, T)$. The riskneutral probability $p_{s}$ is the proxy measure for risk, while the up-movement in firm value $u_{s}$ is the proxy measure for return.

The Cox-Ross-Rubinstein framework is useful in the present context. First, 
the model allows separating consecutive financing rounds into individual binomial steps. The voluntary disclosure requirement of pre-IPO financing rounds brings about the problem of incomplete information on capital transactions and firm valuations. Incomplete information for consecutive financing rounds makes the analysis of compound option pricing models unfeasible. Second, firms do not follow an identical financing pattern as they advance through different stages of development. Some firms are successful in raising sufficient finance to skip entire stages of development, whereas other firms require several injections of capital for a single stage of development. The binomial framework can be adapted to suit any number of financing rounds. Third, the Cox-Ross-Rubinstein framework operates in discrete time steps. This is a necessary condition for the present analysis, because the valuation at consecutive financing rounds is only observable at discrete points in time.

To validate the estimation accuracy of the Cox-Ross-Rubinstein framework, I calculate the ex ante return $\hat{u}$ for each stage $s$ by re-arranging Eq. (2):

$$
\hat{u}_{s}=\frac{e^{r_{f, s}(T-t)_{s}}+\left(e^{2 r_{f . s}(T-t)_{s}}-4 \hat{p}_{s}\left(1-\hat{p}_{s}\right)\right)^{0.5}}{2 \hat{p}_{s}}
$$

where $\hat{p}_{s}$ is the fitted risk-neutral probability. First, I have to estimate the value of $\hat{p}_{s}$ before I can calculate $\hat{u}_{s}$. The fitted risk-neutral probability $\hat{p}_{s}$ comes from the fitted model parameters and the value of the independent variables obtained from the in-sample estimation. For the linear regression model, the regression coefficients are the fitted model parameters. In the case of the neural networks, the connection weights obtained during the neural learning (training) are the fitted model parameters.

The independent variables used to estimate the risk-neutral probabilities at each financing round includes the stage of development, the number of prior financing rounds, the length of time between financing rounds, and the level of investor syndication. The offer price and the partial adjustment in the offer price, are two additional independent variables to explain the risk-neutral probabilities at initial public offering financing rounds. The return on the stock market, the aggregate average underpricing, and the aggregate number of initial public offerings, control for the market conditions. To validate the estimation accuracy of the Cox-Ross-Rubinstein framework, I repeat the calculations in Eq. (2) and Eq. (4) with estimates of the risk-adjusted rates of return from Ruhnka and Young (1987, 1991). 


\section{Data}

Thomson Reuters' VentureExpert and New Issues database contain the data on venture capital and initial public offering financing rounds. VentureXpert provides the data on venture capital deals, including the post-money valuations, the capital injected, the number of venture capital investors, the industry classification of the firm, and the dates for each financing round. In addition, VentureXpert supplies the classification for the different stages of development. They are early stage, expansion, and later stage of development. Early-stage investments normally provide capital for the initial product development, manufacturing, sales and marketing. Investments at the expansion stage supply capital to expand the current operations of firms. Later-stage investments normally provide capital to firms with established products or services. This round typically constitutes the last source of funding before venture capital firms exit from their investment through a trade sale or initial public offering.

The New Issues database supplies the data on initial public offerings, including the offer price, the relative change between the actual offer price and the expected price from the preliminary prospectus offer price range. Thomson Reuters provides 3,926 United States pre-IPO venture capital financing rounds of 1,360 venture capital-backed firms, which obtained a listing between January, 1986 and December, 2008. Jay Ritter's web page provides the monthly average underpricing and the number of initial public offerings. ${ }^{8}$ Thomson Financial Datastream provides the equity market (Nasdaq) return and the risk-free rate of return. The estimates of the risk-adjusted rates of return at different stages of development are from Ruhnka and Young $(1987,1991)$. The rates are $54.8 \%$ for early stage, $42.2 \%$ for expansion, and $35.0 \%$ for later stage of development.

Table 1 presents the annual sample distribution of the sample financing rounds.

\section{[ Table 1]}

Columns [2] and [3] report the number and the percentage of venture capital financing rounds by calendar year. The number of venture capital financing rounds increases from 1986 onwards, peaks in 1999, and then subsequently decreases again. Columns [4] to [9] report the number and the percentage of venture capital rounds across the early, the expansion, and the later stage of development. The expansion stage accounts for $42.46 \%$ of the total venture 
capital financing rounds, followed by the early stage (28.96\%), and the later stage $(28.58 \%)$ of development. The annual distributions of rounds across the different stages of development follow a similar pattern to that of the total venture capital financing rounds. Columns [10] and [11] list the number and the percentage of initial public offering financing rounds by calendar year. The distribution of the initial public offerings is similar to the venture capital financing rounds.

Table 2 shows the sample distribution of financing rounds across the Fama and French (1997) 48-industry classification. Column [1] lists the industry. 39 out of 48 industries $(81.25 \%)$ have attracted venture capital investments and funding from initial public offerings.

\section{[ Table 2 ]}

Columns [2] and [3] report the total number and the percentage of venture capital financing rounds. Venture capital financing rounds show a high concentration in a few industries and reflect the characteristics of venture capital investments. The top five industries include Business Services (34.46\%), Pharmaceutical Products, (15.94\%), Electronic Equipment (10.62\%), Medical Equipment $(9.32 \%)$, and Computers (5.30\%). These sectors account for more than a combined $75 \%$ of all venture capital financing rounds. Columns between [4] and [9] list the number and the percentage of the early stage, the expansion, and the later stages of development. Columns [10] and [11] state the number and the percentage of initial public offerings across industries. The concentration of initial public offerings follows a similar pattern to that of venture capital financing rounds.

Table 3 lists the variables and Table 4 presents the summary statistics. The sample firms have a mean risk-neutral probability $p$ of $33.38 \%$ for venture capital financing rounds and $28.73 \%$ for initial public offering financing rounds. In contrast, the mean risk-adjusted probability $q$ is $45.05 \%$ for venture capital financing rounds and $39.42 \%$ for initial public offering financing rounds. The mean risk-adjusted rate of return is at least six times that of the risk-free rate of return across the financing rounds. The mean multiplier on firm value $u$ is 3.5 and 4.9 for venture capital and initial public offering financing rounds, respectively. $u$ has a high variation and reflects the high growth potential of the sample firms across the different stages of development. In this study, the risk- 
neutral probability $p$ and the risk-adjusted probability $q$ are the proxy measures for risk, while the multiplier on firm value $u$ between consecutive financing rounds is the proxy measure for return.

\section{[ Table 3 ]}

[ Table 4 ]

A zero-one dummy variable captures the early stage of development of the prevous financing round. This variable features only in the risk-return estimation of venture capital financing rounds. The random allocation of observations to training, validation and test data sets for neural network estimation does not always guarantee sufficient variation in the values of this variable. My sample firms have a mean of 2.6 financing rounds prior to the current round, whereas initial public offering financings have a higher mean of 3.3 financing rounds prior to the current round. Investors have injected a mean of US\$ 32.3 million at venture capital financing rounds. The mean capital raised at the initial public offering financing round is US\$ 71.7 and hence more than twice the amount for venture capital financing rounds. It takes an average of 1.0 year and 1.3 years between financing rounds for venture capital and initial public offerings, respectively. A mean of 4.0 investors injected venture capital at the financing round prior to the current round. The number of investors captures the level of syndication. An average of 4.5 investors injected capital prior to the IPO financing round. The mean offer price per share is US\$13.03. $5.82 \%$ is the relative price change between the actual IPO price and the expected price from the preliminary prospectus offer price range. The remaining variables capture equity market and new issues market conditions. The mean Nasdaq return between consecutive financing rounds is $18.04 \%$ for venture capital and $20.04 \%$ for initial public offering financing rounds. The mean underpricing of firms obtaining a stock market listing is similar for firms at venture capital or initial public offering rounds. An average of 40.0 firms have obtained a stock market listing during the month of the current venture capital financing round, whereas the mean is 4.5 for initial public offering rounds.

However, the dataset used in this study does have limitations. All sample firms have obtained venture capital investments and gone through a successful initial public offering. Therefore, the sample firms are more likely to have an increase in value leading up to the initial public offering. This upward trend 
could potentially bias the findings of the present study. A more balanced sample with decreasing firm value between financing rounds could overcome this bias. Unfortunately, privately held firms are more likely to disclose information on deals and valuation if firm value increases. It is much more common to conceal information on decreases in firm value between financing rounds. ${ }^{9}$ Decreases in firm value could discourage future venture capital investments. Nevertheless, the VentureXpert database represents one of the best publicly available datasets.

\section{Estimation models}

This section provides an overview of the different models to estimate the CoxRoss-Rubinstein model parameters. In this study, I use linear regression models, conventional multilayer perceptron neural networks, and cascade neural networks. The multilayer perceptron is a pure nonlinear estimation model, whereas the cascade neural network nests both the linear and nonlinear functional estimation form.

\subsection{Linear regression (Linear)}

A simple linear ordinary least squares regression is the first benchmark model:

$$
p_{s}=\beta_{0}+\sum_{i=1}^{i *} \beta_{i} x_{i, s}+\varepsilon_{s}
$$

where $p$ is the risk-neutral probability for each financing round $s . x$ is the set of explanatory variables $i=1, \ldots, i * . \beta_{0}$ is the constant term, $\beta_{i}$ are the regression coefficients, and $\varepsilon$ is the error term. The Jarque-Bera (1980) test for normality and White's (1980) test for heteroskedasticity show that the regression residuals are not well-behaved. Variable transformations cannot alleviate the problem and hence the t-statistics use White's (1980) heteroskedasticity consistent standard errors and covariances. The Lee-White-Granger (1993) test identifies neglected nonlinearity in the regression residuals. Therefore, since the functional form of the nonlinearity is unknown, the present study resorts to artificial neural networks. 


\subsection{Multilayer perceptron neural network (MLP)}

The conventional multilayer perceptron neural network (Rosenblatt, 1961; Rumelhart, Hinton and Williams, 1986) is the second benchmark model. Neural networks detect patterns from the underlying data through processing elements connected together. These processing elements (known as neurons) are arranged in two layers: the input and output layer. The number of neurons in the input layer corresponds to the number of input (independent) variables, whereas the number of output neurons in the output layer corresponds to the number of output (dependent) variables. Between the input and output layer is the hidden layer, which also has neurons. The purpose of the hidden layer is to identify the nonlinear pattern and interaction effects between the input and output variables. Each neuron in the hidden layer and the output layer receives signals from other neurons, whereas the input layer neurons receive their signals from the input variables. The strength of the input signals from each neuron is stored in the connection weights. A nonlinear transfer function is then applied to the sum of the input connection weights to form the output signal of a neuron. Accordingly, the multilayer perceptron has the following form:

$$
\begin{gathered}
n_{k, s}=\omega_{k, 0}+\sum_{i=1}^{i *} \omega_{k, s} x_{i, s} \\
N_{k, s}=T\left(n_{k, s}\right)=\frac{e^{n_{k, s}}-e^{-n_{k, s}}}{e^{n_{k, s}}+e^{-n_{k, s}}} \\
p_{s}=\gamma_{0}+\sum_{k=1}^{k *} \gamma_{k} N_{k, s}+\varepsilon_{s}
\end{gathered}
$$

where $T\left(n_{k, s}\right)$ is the tansig activation function, $i *$ are the input variables $x$, and $k *$ is the number of neurons. A linear combination of the input variables $x_{i, s}, i=1, \ldots, i *$, for each stage $s$, which the input weights $\omega_{k, i}, i=1, \ldots, i *$ and the constant weight bias $w_{k, 0}$ form the variable $n_{k, s}$. The activation function squashes the $n_{k, s}$ variable to take on a value of $N_{k, s}$ for each observation $s . \gamma_{0}$ is the weight bias of the output neuron.

Neural learning (or training) determines the optimal value of the interconnection weights to minimise the estimation error between the input and output variables. Learning starts from initial randomised weights. The learning algorithm adjusts the weights repeatedly to minimise the difference between the output produced and the output desired of the dependent variable. In accordance 
with common practice, I divide the data into a training set, cross-validation set, and test set.

The purpose of the training set is to estimate the connection weights. The cross-validation set monitors the learning progress and terminates the training as soon as the estimation error increases, to avoid overfitting a model to the data. Finally, the test set evaluates the estimation performance on previously unseen data.

However, a challenge arises in the multilayer perceptron architecture because the researcher needs to decide on the connectivity of the neurons in the hidden layer. Deciding on this connectivity directly affects the estimation performance. The cascade neural network architecture determines the connectivity of neurons from the data rather than having it enforced by the researcher.

\subsection{Cascade neural network (Cascade)}

I use the cascade neural network architecture as advocated in Fahlman and Lebiere (1990). In this architecture, the input variables are not only linked through the hidden layer of the squashed tansig functions, but also have direct linear links to the output variable. ${ }^{10}$

$$
\begin{gathered}
n_{k, s}=\omega_{k, 0}+\sum_{i=1}^{i *} \omega_{k, s} x_{i, s} \\
N_{k, s}=T\left(n_{k, s}\right)=\frac{e^{n_{k, s}}-e^{-n_{k, s}}}{e^{n_{k, s}}+e^{-n_{k, s}}} \\
p_{s}=\gamma_{0}+\sum_{k=1}^{k *} \gamma_{k} N_{k, s}+\sum_{i=1}^{i *} \beta_{i} x_{i, s}+\varepsilon_{s}
\end{gathered}
$$

The cascade architecture nests both the multilayer perceptron and the linear model. This configuration allows for the possibility of combined linear and nonlinear functional components. Cascade neural networks are particularly useful in situations where there is no clear a priori expectation about the underlying functional form. In the conventional multilayer perceptron neural network, the researcher needs to determine the number of hidden nodes and their connectivity

to minimise the estimation error. In the cascade architecture, the hidden nodes are determined by the data endogenously and not enforced by the researcher. Cascade learning starts off with no hidden neurons. The only connections are 
the direct ones between the neurons in the input and the output layer. Hidden nodes are added one at the time and the estimation error re-calculated. The cascade algorithm adds additional hidden nodes until no further improvement in the estimation performance takes place.

\subsection{Model performance}

In this paper, I use the Hannan and Quinn (1979) information criterion (HQIFC) in the model building process to test the estimation accuracy. The HQIFC measure penalises the estimation error for the number of model parameters. More complex neural network models have an increasing number of model parameters when compared to the linear regression models. The HQIFC measure, therefore, allows for a better estimation comparison between different model complexities. I use Granger and Jeon's (2004) 'thick' modelling technique which relies on trimmed mean estimates of repeatedly trained neural networks. This approach provides stable estimates across different architectures. In addition to the HQIFC measure, I also use traditional performance measures, including the sum of squared errors (SSE), the mean squared error (MSE), and the coefficient of determination (R-squared).

\subsection{Variable significance testing}

In this study, I perform variable significance testing to assess the relevance of the explanatory variables across all estimation models. In nonlinear relationships, the functional form between the explanatory and the dependent variables only requires that the conditional expectation varies with an increasing value in the independent variable. The approach in variable significance testing used in linear regression analysis is, therefore, not useful in detecting symmetric or periodic nonlinear functions. Instead, I analyse the impact of the explanatory variables on the sensitivity of the model fitness as advocated in Refenes and Zapranis (1999). I use the HQIFC as the model-fitness sensitivity measure. An explanatory variable is significant only if its inclusion leads to an improvement in the HQIFC. I calculate the HQIFC sample variance by means of re-sampling with replacement (bootstrap) to obtain empirical probability density functions. Testing that variable $x_{i}$ is statistically significant takes the form of $\operatorname{H0:} \operatorname{HQIFC}\left(x_{i}\right)$

$=\mathrm{HQIFC}$ against the alternative $\operatorname{HA}: \operatorname{HQIFC}\left(x_{i}\right)<\operatorname{HQIFC}$ and involves a 
t-test.

\subsection{Out-of-sample testing}

I apply the 0.632 bootstrap method to validate the estimation the error of the different models. This approach is based on Efron $(1979,1983) .{ }^{11}$ I estimate the in-sample estimation error $\hat{e}^{2}$ as the difference between the actual and the fitted values from the different model parameters and their functional approximations $f$, as

$$
\hat{e}^{2}=\frac{1}{n} \sum_{i=1}^{n}\left(y_{i}-f\left(x_{i}, \hat{b}\right)\right)^{2}
$$

where $y_{i}$ is the actual value, $f(\cdot)$ is the estimated value of $y_{i}$ from the fitted regression parameters $\hat{b}$ and the independent variables $x_{i}$ using the sample length $n$ of the entire estimation set. The bootstrapping procedure involves drawing $n$ observations with replacement from the original sample length $n$ and allocating these observations to the new estimation set $Q$. I use $Q$ to estimate the model parameters $\hat{b}$. Some of the observations in $Q$ will be repeated, while others will not have been picked. Unselected observations are allocated to the out-ofsample test dataset. I then estimate the error $\hat{e}_{(0)}$ for those observations, which appear in the test dataset from $m$ bootstrap replications,

$$
\hat{e}_{(0)}=\frac{1}{m} \sum_{j=1}^{m} \frac{1}{\#(i \notin Q)} \sum_{i \notin Q}\left(y_{i}-f\left(x_{i}, \hat{b}_{(Q)}\right)\right)^{2}
$$

To calculate the 0.632 bootstrap error, I take account of the in-sample bias adjustment,

$$
\hat{\omega}_{(0.632)}=0.632\left(\hat{e}_{(0)}-\hat{e}^{2}\right)
$$

to calculate $\hat{e}_{(0.632)}$,

$$
\hat{e}_{(0.632)}=\hat{e}^{2}+\hat{\omega}_{(0.632)}
$$

or, equivalently,

$$
\hat{e}_{(0.632)}=0.368\left(\hat{e}^{2}\right)+0.632\left(\hat{e}_{(0)}\right)
$$


The weighting of 0.632 and 0.368 comes from the probability of observations ending up in the estimation or the out-of-sample datasets. For example, a particular observation has a probability of $(1-1 / n)$ not being picked for the

estimation set. Therefore, for a large dataset, the probability of ending up in the out-of-sample dataset after $n$ draws with replacement is approximately

$$
\left(1-\frac{1}{n}\right)^{n} \approx e^{-1} \approx 0.368
$$

It follows from Eq. (17) that approximately $63.2 \%$ of the observations end up in the estimation dataset for any one bootstrap replication. Unfortunately, the 0.632 error estimate does not follow a well-defined distribution. Therefore, I cannot test if $\hat{e}_{(0.632)}^{\tau}$ from model $\tau$ is significantly different from $\hat{e}_{(0.632)}^{v}$ of model $v$.

I calculate the 0.632 bootstrap ratio (BR) to measure the 'thick' estimation errors relative to the ones obtained from the linear benchmark models. A BR value of less than one indicates a gain for the 'thick' models over the linear benchmark regressions. In addition to the BR measure, I use the sum of squared estimation errors (SSE), the mean squared error (MSE), the root mean squared error (RMSQ), the mean absolute error (MAE), and the correlation coefficient $(\mathrm{R})$ between the ex ante and ex post values.

I use the estimation models presented in this section to estimate the probabilities of an up-movement in firm value. An accurate approximation of the success probabilities is an important intermediary step. The fitted probabilities are used to calculate the ex ante returns from the Cox-Ross-Rubinstein model in Eq. (4).

\section{$5 \quad$ Findings}

In this paper, I argue that estimating the Cox-Ross-Rubinstein model parameters with cascade neural networks provides better estimation accuracy of the risk-return profile than risk-adjusted valuation approaches, conventional neural networks, and linear benchmark models. The findings are persistent across in-sample and out-of-sample tests using 3,926 venture capital and 1,360 US initial public offering financing rounds between January, 1989 and December 2008. However, the estimation error across the different performance measures remains relatively high. High estimation errors are consistent with common ob- 
servations of new venture investments which can have extreme outcomes in risk and return.

\subsection{In-sample performance}

Table 5 presents the in-sample model performances of the estimation models to explain the risk-neutral probabilities of an up-movement in firm value at financing rounds.

\section{[ Table 5 ]}

The cascade neural network (Cascade) estimates are more accurate than those of the multilayer perceptron (MLP) and the linear benchmark model (Linear). This finding is not surprising since the cascade neural networks nest both the linear and nonlinear estimation models.

The outperformance of the cascade neural networks is compelling across all venture capital financing rounds (Panel A) and initial public offering financing rounds (Panel B). The Hannnan-Quinn information criterion (HQIFC), the sum of squared error (SSE) and the mean squared error (MSE) have the smallest values, while the coefficient of determination (R-squared) has the highest values. The coefficients of determination have similar values to the R-squared reported in Seppä and Laamanen (2001). ${ }^{12}$ The mean squared error (MSE) confirms that the partial adjustment in the offer price (Hanley, 1993) improves the estimation accuracy if we compare the initial public offering financing rounds (Panel B) with the venture capital financing rounds (Panel A).

Both the Lee-White-Granger and the Jarque-Bera test indicate that the residuals are not well behaved across all estimation models. The Lee-WhiteGranger test indicates the presence of neglected nonlinearity in the residuals of the linear regression models. In Panel A, we can reject linearity outright, while in Panel B, 302 out of the one thousand randomly generated nonlinear combinations of the predictor variables are statistically significant in explaining the residuals of the linear benchmark model. The Jarque-Bera test rejects normality of the residuals across all estimation models. This result reflects the actual nature of the risk-return profile of venture capital and initial public offering financing rounds. The variation in the risk-return profile for this type of firms is very high. 
Table 6 shows the results of the variable significance testing. The riskneutral approach is consistent with the model predictions on the risk-return characteristics of venture capital and initial public offering financing rounds. All variables in the estimation models are statistically significant at the $10 \%$ level. For those variables, which are not statistically significant, variable deletion tests show deterioration in the estimation accuracy when excluded. Therefore, these variables remain in the final model. Although the neural networks have fewer predictor variables, the estimates of these models are more accurate than the estimates of the linear regressions. The better performance of the cascade neural network is due to its ability to take account of variable interaction effects together with the nonlinear and linear functional form.

\section{[ Table 6 ]}

The significance of the variables is, by and large, consistent with the extant knowledge of venture capital and initial public offering financing rounds. Knowing the statistical significance of the independent variables is an important intermediary step in estimating the ex ante probabilities and, in turn, the ex ante up-movement in firm value.

Only regression analysis allows statements to be made about the direction of the relationship between the risk-neutral probabilities and the independent variables. Testing of the variable significance in neural networks involves testing the null hypothesis of no underlying pattern and the variable wrongly entering the estimation models.

Early-stage investments have higher implied risk than firms at higher stages of development. More frequent financing rounds, an increasing number of investors, and larger amounts of capital injected have lower risk. The risk reduces for an increasing length of time between two consecutive financing rounds. Positive adjustments in the initial public offering prices between the preliminary and the actual offer price have smaller risk-neutral probabilities. Higher offer prices also have smaller risk-neutral probabilities. Consistent with the risk-neutral framework, the market return has a negative correlation with the risk-neutral probabilities. The market return has a negative association with the risk-neutral success probabilities. The number of initial public offerings during the month of the current financing round has a negative correlation with the risk-neutral success probabilities. The relationship between the IPO return of companies 
during the month of the current financing round and the risk-neutral success probabilities is inconclusive. The association is positive in the case of venture capital investments and negative in the case of initial public offering financing rounds. This reversed direction of the relationship could be an indication of an over-specified linear model. However, the variable inflation factors (VIF) do not raise any concerns for the problem of multicollinearity.

\subsection{Out-of-sample performance}

Table 7 presents the out-of-sample tests on the estimation accuracy of the success probabilities on the up-movement in firm value between two consecutive financing rounds, the proxy measure for risk.

\section{[ Table 7 ]}

Overall, the estimation errors of the risk-neutral framework are smaller than the risk-adjusted approach across the performance measures. There is only one exception in which the correlation coefficient $(\mathrm{R})$ shows a better fit for the riskadjusted framework when compared to the risk-neutral framework. The majority of the performance measures which compare the different estimation models favour the cascade neural networks (Cascade) compared to the benchmark models. There are only three exceptions in which the multilayer perceptron provides more accurate estimates. These exceptions are for the correlation coefficient $(\mathrm{R})$ in the risk-neutral framework (in Panel A), the 0.632 bootstrap ratio (BR) in the risk-neutral and risk-adjusted framework (in Panel B).

Table 8 presents the estimation accuracy of the up-movements in firm value based on the fitted probabilities for each of the estimation models. The upmovement in firm value is the proxy measure for return.

\section{[ Table 8]}

Overall, the risk-neutral framework provides more accurate estimates in the upmovement in firm value between consecutive financing rounds when compared to the risk-adjusted approach. There are only two exceptions. The correlation coefficient between the ex ante and the ex post values for the risk-neutral 
framework are lower for the multilayer perceptron (MLP) and the cascade neural networks (Cascade) in Panel B. The majority of performance measures show that the cascade neural networks (Cascade) outperform their benchmark models. There are, again, only two exceptions to the rule. In Panel A, the correlation coefficient (R) and the mean absolute error (MAE) have higher estimation errors in the case of the Cascade model than the MLP model.

The smaller estimation errors of the risk-neutral approach that relies on the parameter estimation using cascade neural networks are likely to come from the lower heterogeneity in the risk-free rates of return than the risk-adjusted rates of return, and the estimation flexibility of cascade neural networks. Cascade neural networks nest both the linear and nonlinear functional estimation form. They also take account of any variable interaction effects without having to model them a priori.

\section{$6 \quad$ Extensions}

There are many ways to extend this study. My selection of the Cox-RossRubinstein (1979) is crude. More sophisticated or alternative risk-neutral approaches may be available to improve the risk-return estimation accuracy. However, these techniques need to be able to overcome some of the challenges when using large samples. For example, the length of the time between consecutive financing rounds differ and new venture firms do not follow an identical sequential pattern in financing rounds to fund key development stages.

More sophisticated estimation techniques could also improve the risk-return estimation accuracy. However, I do not claim that the 'thick' neural network models are the only alternative to linear regressions or indeed superior to other estimation techniques per se. Neural networks are appealing because they can approximate any functional form without theoretical guidance or prior knowledge. My analysis shows that cascade neural networks which nest both the linear and nonlinear functional form provide the most accurate estimates of the riskreturn profile at financing rounds. However, more sophisticated neural network architectures or alternative estimation techniques are possible directions for future research. Some of these estimation techniques could also try and consider possible structural breaks between venture capital and initial public offerings. Some of the variable significance tests imply that the linear benchmark models 
are overspecified. Parsimonious 'thick' models with fewer independent variables provide more accurate forecasts.

\section{Acknowledgements}

I thank C J Adcock (the editor), two anonymous referees, Huainan Zhao and Lynda Taylor for valuable comments. I am grateful to Jay Ritter for making available the data on aggregate initial public offerings on his web site [http://bear.warrington.ufl.edu/ritter/ipodata.htm]. The Research Committee New Lecturers' Fund (NLF3479) of Nottingham University Business School and The University of Nottingham has supported this research.

\section{References}

1. Admati, Anat R., and Paul Pfleiderer, 1994, Robust financial contracting and the role of venture capitalists, Journal of Finance 49, 371-402.

2. AlFuhaid, A. S., and M. A. El-Sayed, 1997, Cascaded artificial neural networks for short-term load, IEEE Transactions on Power Systems 12, 1524 .

3. Billio, Monica, Domenico Sartore, and Carlo Toffano, 2000, Combining forecasts: Some results on exchange and interest rates, European Journal of Finance 6, 126-145.

4. Brock, Wiliam, Josef Lakonishok, and Blake LeBaron, 1992, Simple technical trading rules and the stochastic properties of stock returns, Journal of Finance 47, 1731-1764.

5. Casamatta, Catherine, and Carole Haritchabalet, 2007, Experience, screening and syndication in venture capital investments, Journal of Financial Intermediation 16, 368-398.

6. Cooper, John C. B., 1999, Artificial neural networks versus multivariate statistics: An application from economics, Journal of Applied Statistics 26, 909-921.

7. Cox, John C., Stephen A. Ross, and Mark Rubinstein, 1979, Option pricing: A simplified approach, Journal of Financial Economics 7, 229-263.

8. Dunis, Christian L., Jason Laws, and Ben Evans, 2008, Trading futures spread portfolios: Applications of higher order and recurrent networks, European Journal of Finance 14, 503-521.

9. Efron, Bradley, 1979, Bootstrap methods: Another look at the jackknife, The Annals of Statistics 7, 1-26. 
10. Efron, Bradley, 1983, Estimating the error rate of a prediction rule: Improvement on cross-validation, Journal of the American Statistical Association $78,316-331$.

11. Efron, Bradley, and Robert J. Tibshirani, 1993. An introduction to the bootstrap (Chapman \& Hall, London).

12. Fahlman, Scott E., and Christian Lebiere, 1990, The cascade-correlation learning architecture, in D. S. Touretzky, ed.: Advances in neural information processing systems (Morgan-Kaufmann, Los Altos CA).

13. Fama, Eugene F., and Kenneth R. French, 1997, Industry costs of equity, Journal of Financial Economics 43, 153-193.

14. Franses, Philip Hans, and Dick van Dijk, 2000. Non-linear time series models in empirical finance (Cambridge University Press, Cambridge, United Kingdom).

15. Gompers, Paul, and Josh Lerner, 2000, Money chasing deals? The impact of fund inflows on private equity valuation, Journal of Financial Economics $55,281-325$.

16. Granger, Clive W. J., and Yongil Jeon, 2004, Thick modeling, Economic Modelling 21, 323-343.

17. Hall, Peter, 1995. The bootstrap and edgeworth expansion (Springer, Berlin).

18. Hanley, Kathleen Weiss, 1993, The underpricing of initial public offerings and the partial adjustment phenomenon, Journal of Financial Economics $34,231-250$.

19. Hannan, E. J., and B. G. Quinn, 1979, The determination of the order of an autoregression, Journal of the Royal Statistical Society. Series B (Methodological) 41, 190-195.

20. Hornik, Kurt, Maxwell Stinchcombe, and Halbert White, 1989, Multilayer feedforward networks are universal approximators, Neural Networks 2, 359-366.

21. Hutchinson, James M., Andrew W. Lo, and Tomaso Poggio, 1994, A nonparametric approach to pricing and hedging derivative securities via learning networks, Journal of Finance 49, 851-889.

22. Jarque, Carlos M., and Anil K. Bera, 1980, Efficient tests for normality, homoscedasticity and serial independence of regression residuals, Economics Letters 6, 255-259.

23. Kosowski, Robert, Narayan Y. Naik, and Melvyn Teo, 2007, Do hedge funds deliver alpha? A bayesian and bootstrap analysis, Journal of Financial Economics 84, 229-264. 
24. Kothari, S. P., and Jay Shanken, 1997, Book-to-market, dividend yield, and expected market returns: A time-series analysis, Journal of Financial Economics 44, 169-203.

25. Kothari, S. P., and Jerold B. Warner, 1997, Measuring long-horizon security price performance, Journal of Financial Economics 43, 301-339.

26. Lee, Tae-Hwy, Halbert White, and Clive W. J. Granger, 1993, Testing for neglected nonlinearity in time series models : A comparison of neural network methods and alternative tests, Journal of Econometrics 56, 269290.

27. Loughran, Tim, and Jay Ritter, 2004, Why has ipo underpricing changed over time?, Financial Management 33, 5-37.

28. Lowry, Michelle, 2003, Why does ipo volume fluctuate so much?, Journal of Financial Economics 67, 3-40.

29. Malik, Farooq, and Mahdi Nasereddin, 2006, Forecasting output using oil prices: A cascaded artificial neural network approach, Journal of Economics \& Business 58, 168-180.

30. McNelis, Paul D., and Naoyuki Yoshino, 2004, Deciphering the message in japanese deflation dynamics, Asian Economic Papers 3, 49-70.

31. Refenes, A.-P. N., and A. D. Zapranis, 1999, Neural model identification, variable selection and model adequacy, Journal of Forecasting 18, 299-322.

32. Rosenblatt, F., 1961, Principles of Neurodynamics, Washington, D.C., Spartan Press

33. Ruhnka, John C., and John E. Young, 1987, A venture capital model of the development process for new ventures, Journal of Business Venturing $2,167-184$.

34. Ruhnka, John C., and John E. Young, 1991, Some hypotheses about risk in venture capital investing, Journal of Business Venturing 6, 115-133.

35. Rumelhart, D.E., G.E. Hinton, and R.J. Williams, 1986, Learning internal representations by error propagation, in D.E. Rumelhart and J.L. McClelland, Eds., Parallel Data Processing, Vol. 1, Cambridge, MA: The M.I.T. Press, pp. 318-362.

36. Sahlman, William A., 1993, Aspects of financial contracting in venture capital, in Donald H. Chew, ed.: The new corporate finance: Where theory meets practice (McGraw-Hill, New York).

37. Seppä, Tuukka J., and Tomi Laamanen, 2001, Valuation of venture capital investments: Empirical evidence, R\&D Management 31, 215-230. 
38. Wetzel, W. E., 1981, Informal risk capital in new england, in K. H. Vesper, ed.: Frontiers of entrepreneurial reseaerch (Babson College, Wellesley, MA).

39. White, Halbert, 1980, A heteroskedasticity-consistent covariance matrix estimator and a direct test for heteroskedasticity, Econometrica 48, 817838.

40. Yung, Chris, Gönül Çolak, and Wang Wei, 2008, Cycles in the ipo market, Journal of Financial Economics 89, 192-208.

41. Zhang, Guoqiang, B. Eddy Patuwo, and Michael Y. Hu, 1998, Forecasting with artificial neural networks: The state of the art, International Journal of Forecasting 14, 35-62. 


\section{Notes}

${ }^{1}$ Sahlman (1993) identifies three options for venture capital firms: the option to re-value an investment, the option to inject additional capital, and the option to abandon an investment.

${ }^{2}$ Estimates of the risk-adjusted rates of return in Ruhnka and Young (1987, 1991) are: $54.8 \%$ for early stage, $42.2 \%$ for expansion stage, $35.0 \%$ for later stage of development of venture capital investments.

${ }^{3}$ The following example illustrates the two approaches. Say there is an equal probability that cash flow payouts of a firm are $\$ 1$ or $\$ 0$ after one period. Assume that these cash flow payouts are risky. If the risk-adjusted discount rate is $20 \%$ the expected firm value is $(0.5 \times \$ 1+0.5 \times \$ 0) \times e^{-0.2 \times 1}=\$ 0.41$. This is the risk-adjusted expected firm value in present dollars. We can also obtain the $\$ 0.41$ from the same original payouts, but risk-adjusting the probabilities of occurrence of each payout which we then discount at the risk-free rate. Suppose that the risk-free rate is $2.5 \%$. We can calculate the expected $\$ 0.41$ by solving the risk-neutral probability $p$ in $(p \times \$ 1+(1-p) \times \$ 0) \times e^{-0.025 \times 1}=\$ 0.41$ which is $42 \%$.

${ }^{4}$ See, for example, Hornick, Stinchcombe, and White (1989) and Cooper (1999) for details on the neural network methodology. Zhang, Patuwo, and Hu (1998) provide a survey of the literature on artificial neural networks.

${ }^{5}$ See, for example, Billio, Sartore and Toffano (2000), Dunis, Laws and Evans (2008), and Franses and van Dijk (2000) for descriptions of this methodology.

${ }^{6}$ Their sample consists of 597 observations of which 421 are venture capital financing rounds and 176 represent initial public offering financing rounds. The sample period only covers 1998 and 1999.

${ }^{7}$ The sample distribution across industries is unclear in Seppä and Laamanen (2001) and could cast doubt on the generalizability and validity of their findings.

${ }^{8}$ I thank Jai Ritter for making this data publicly available on http://bear. warrington.ufl.edu/ritter/ipodata.htm.

${ }^{9}$ The sample firms show a decrease in firm value in 170 out of $3,926(4.3 \%)$ venture capital financing rounds, and 60 out of 1,360 (4.4\%) initial public offering financing rounds.

${ }^{10}$ For applications see, for example, AlFuhaid and El-Sayed (1997) and McNelis and Yoshino (2004).

${ }^{11}$ For a detailed discussion of the bootstrap method see, for example, Efron and Tibshirani (1993) or Hall (1995). Studies applying bootstrapping include, for example, Brock, Lakonishok and LeBaron (1992), Kosowski, Naik and Teo (2007), Kothari and Shanken (1997), Kothari and Warner (1997), etc.

${ }^{12}$ They report a coefficient of determination of 0.22 to explain the risk-neutral probabilities. 
Table 1: Sample distribution across calendar year

This table presents the sample distribution of the venture capital and initial public offering financing rounds across the calendar years. The sample consists of 3,926 venture capital financing rounds and 1,360 initial public offering financing rounds between January, 1986 and December, 2008, identified from Thomson Reuters' VentureXpert and New Issues database. Column [1] reports the calendar year. Columns [2] and [3] report the number and the percentage of venture capital financing rounds by calendar year. Columns [4] and [5] state the number and the percentage of early stage financing rounds in relation to the total vent ure capital financing rounds. Columns [6] and [7] describe the number and the percentage of expansion stage financing rounds in relation to the total venture capital financing rounds. Columns [8] and [9] convey the number and the percentage of later stage financing rounds in relation to the total venture capital financing rounds. The early stage, expansion, and later stages of development classification of financing rounds are from the VentureXpert database. Columns [10] and [11] report the number and the percentage of initial public offering financing rounds in relation to the total initial public offering financing rounds by calendar year.

\begin{tabular}{|c|c|c|c|c|c|c|c|c|c|c|}
\hline \multirow[b]{2}{*}{ Year } & \multicolumn{2}{|c|}{ Total } & \multicolumn{2}{|c|}{ Early stage } & \multicolumn{2}{|c|}{ Expansion } & \multicolumn{2}{|c|}{ Later stage } & \multicolumn{2}{|c|}{ IPO } \\
\hline & $\mathrm{N}$ & $\%$ & $\mathrm{~N}$ & $\%$ & $\mathrm{~N}$ & $\%$ & $\mathrm{~N}$ & $\%$ & $\mathrm{~N}$ & $\%$ \\
\hline [1] & {$[2]$} & [3] & [4] & [5] & [6] & {$[7]$} & [8] & {$[9]$} & {$[10]$} & [11] \\
\hline 1986 & 6 & 0.15 & 3 & 50.00 & 2 & 33.33 & 1 & 16.67 & 0 & 0.00 \\
\hline 1987 & 4 & 0.10 & 3 & 75.00 & 1 & 25.00 & 0 & 0.00 & 0 & 0.00 \\
\hline 1988 & 9 & 0.23 & 5 & 55.56 & 2 & 22.22 & 2 & 22.22 & 1 & 0.07 \\
\hline 1989 & 17 & 0.43 & 13 & 76.47 & 3 & 17.65 & 1 & 5.88 & 0 & 0.00 \\
\hline 1990 & 20 & 0.51 & 12 & 60.00 & 4 & 20.00 & 4 & 20.00 & 3 & 0.22 \\
\hline 1991 & 30 & 0.76 & 16 & 53.33 & 12 & 40.00 & 2 & 6.67 & 7 & 0.51 \\
\hline 1992 & 60 & 1.53 & 31 & 51.67 & 17 & 28.33 & 12 & 20.00 & 16 & 1.18 \\
\hline 1993 & 115 & 2.93 & 37 & 32.17 & 46 & 40.00 & 32 & 27.83 & 40 & 2.94 \\
\hline 1994 & 138 & 3.52 & 62 & 44.93 & 50 & 36.23 & 26 & 18.84 & 25 & 1.84 \\
\hline 1995 & 276 & 7.03 & 86 & 31.16 & 129 & 46.74 & 61 & 22.10 & 106 & 7.79 \\
\hline 1996 & 381 & 9.70 & 162 & 42.52 & 151 & 39.63 & 68 & 17.85 & 156 & 11.47 \\
\hline 1997 & 417 & 10.62 & 201 & 48.20 & 151 & 36.21 & 65 & 15.59 & 106 & 7.79 \\
\hline 1998 & 412 & 10.49 & 156 & 37.86 & 178 & 43.20 & 78 & 18.93 & 71 & 5.22 \\
\hline 1999 & 672 & 17.12 & 149 & 22.17 & 306 & 45.54 & 217 & 32.29 & 249 & 18.31 \\
\hline 2000 & 437 & 11.13 & 85 & 19.45 & 202 & 46.22 & 150 & 34.32 & 215 & 15.81 \\
\hline 2001 & 159 & 4.05 & 41 & 25.79 & 78 & 49.06 & 40 & 25.16 & 37 & 2.72 \\
\hline 2002 & 106 & 2.70 & 21 & 19.81 & 53 & 50.00 & 32 & 30.19 & 24 & 1.76 \\
\hline 2003 & 144 & 3.67 & 23 & 15.97 & 66 & 45.83 & 55 & 38.19 & 27 & 1.99 \\
\hline 2004 & 198 & 5.04 & 15 & 7.58 & 95 & 47.98 & 88 & 44.44 & 90 & 6.62 \\
\hline 2005 & 128 & 3.26 & 9 & 7.03 & 41 & 32.03 & 78 & 60.94 & 53 & 3.90 \\
\hline 2006 & 104 & 2.65 & 4 & 3.85 & 47 & 45.19 & 53 & 50.96 & 55 & 4.04 \\
\hline 2007 & 87 & 2.22 & 3 & 3.45 & 31 & 35.63 & 53 & 60.92 & 73 & 5.37 \\
\hline \multirow[t]{2}{*}{2008} & 6 & 0.15 & 0 & 0.00 & 2 & 33.33 & 4 & 66.67 & 6 & 0.44 \\
\hline & 3926 & 100.00 & 1137 & 28.96 & 1667 & 42.46 & 1122 & 28.58 & 1360 & 100.00 \\
\hline
\end{tabular}




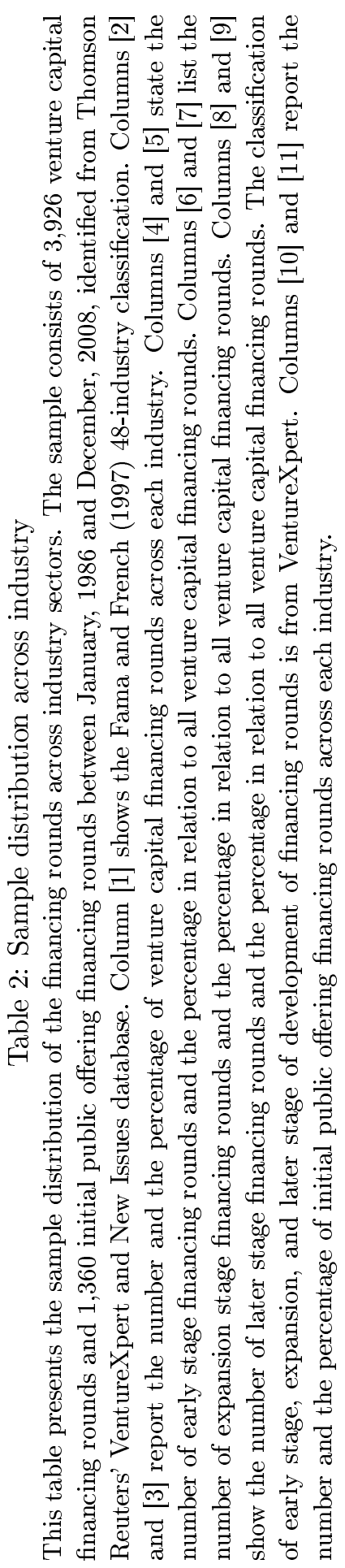




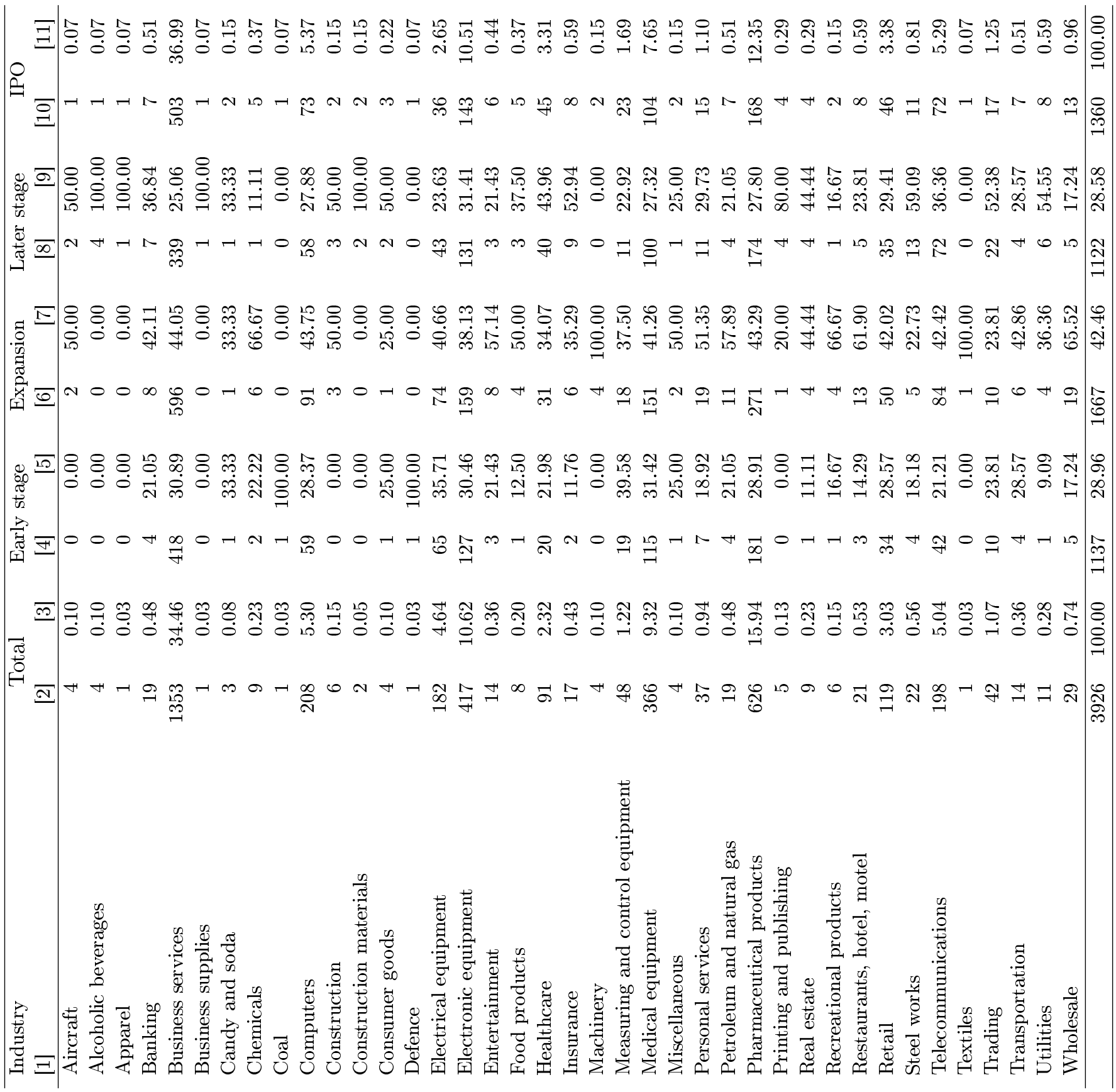


Table 3: Variable definitions

This table presents the definitions of the dependent and the independent variables. The risk-neutral success probability $p$ and the risk-adjusted success probability $q$ are the proxy measures for risk between consecutive financing rounds. The multiplier in the up movement in firm value $u$ is the proxy measure for return between consecutive financing rounds.

\begin{tabular}{|c|c|}
\hline Variable code & Definition \\
\hline$p$ & $\begin{array}{l}\text { The Cox-Ross-Rubinstein risk-neutral success probability of an } \\
\text { up-movement in firm value between consecutive financing rounds as } \\
\text { defined in Eq. (2) }\end{array}$ \\
\hline$q$ & $\begin{array}{l}\text { The Cox-Ross-Rubinstein risk-adjusted success probability of an } \\
\text { up-movement in firm value between consecutive financing rounds. } q \text { is } \\
\text { obtained from replacing the continuously compounded five-year } \\
\text { Treasury-bill rate in Eq. (2) with the continuously compounded } \\
\text { risk-adjusted rate of return from Ruhnka and Young }(1987,1991) \text { for } \\
\text { the corresponding development stage. }\end{array}$ \\
\hline$u$ & $\begin{array}{l}\text { The multiplier on firm value between two consecutive financing rounds. } \\
u \text { is the post-money firm value at the current financing round divided } \\
\text { by the post-money firm value at the previous financing round as } \\
\text { defined in Eq. (1). }\end{array}$ \\
\hline$r_{f}$ & The continuously compounded five-year Treasury-bill rate. \\
\hline$r$ & $\begin{array}{l}\text { The continuously compounded risk-adjusted rate of return from } \\
\text { Ruhnka and Young }(1987,1991) \text { for the corresponding development } \\
\text { stage: } 54.8 \% \text { for early-stage, } 42.2 \% \text { for expansion, and } 35 \% \text { for later } \\
\text { stage of development. }\end{array}$ \\
\hline Early & $\begin{array}{l}\text { A dummy variable that is set to one if the firm is at an early stage of } \\
\text { development at the prior venture capital financing round. Early-stage } \\
\text { is identified from the VentureXpert database. }\end{array}$ \\
\hline Rounds & $\begin{array}{l}\text { The total number of financing rounds of a firm prior to the current } \\
\text { financing rounds. }\end{array}$ \\
\hline Capital & $\begin{array}{l}\text { The amount of capital (US\$ million) raised at the current financing } \\
\text { round. }\end{array}$ \\
\hline Time & The time period in years between two consecutive financing rounds. \\
\hline Offer Price & The initial public offering price (US\$) per share. \\
\hline Change price & $\begin{array}{l}\text { Hanley's (1993) partial adjustment in the offer price between the filing } \\
\text { of the preliminary and the final prospectus, identified from Thomson } \\
\text { Reuter's New Issues database. }\end{array}$ \\
\hline Syndication & $\begin{array}{l}\text { The number of venture capital investors at the previous financing } \\
\text { round identified Thomson Reuter's VentureXpert. }\end{array}$ \\
\hline Marketreturn & $\begin{array}{l}\text { The return on the Nasdaq index between two consecutive financing } \\
\text { rounds. }\end{array}$ \\
\hline IPO return & $\begin{array}{l}\text { The equally weighted average initial public offering underpricing during } \\
\text { the month of the current financing round from Jay Ritter's web site [a]. }\end{array}$ \\
\hline Number IPOs & $\begin{array}{l}\text { The total number of initial public offerings during the month of the } \\
\text { current financing rounds from Jay Ritter's web site [a]. }\end{array}$ \\
\hline
\end{tabular}

[a] [http://bear.warrington.ufl.edu/ritter/ipodata.htm] 
Table 4: Summary statistics

This table presents the summary statistics for 3,926 venture capital financing rounds (Panel A) and 1,360 initial public offering financing rounds (Panel B) between January, 1986 and December, 2008. Table 3 provides the variable definitions.

\begin{tabular}{|c|c|c|c|c|c|}
\hline Variable code & Unit & $25 \%$ & Mean & Median & $75 \%$ \\
\hline \multicolumn{6}{|c|}{ Panel A: Venture capital financing rounds } \\
\hline$p$ & & 0.2171 & 0.3338 & 0.3210 & 0.4316 \\
\hline$q$ & & 0.2787 & 0.4504 & 0.4226 & 0.5964 \\
\hline$u$ & & 1.5470 & 3.5100 & 2.3489 & 3.9473 \\
\hline$r_{f}$ & $\%$ & 4.8522 & 5.3620 & 5.5638 & 6.0269 \\
\hline$r$ & $\%$ & 30.0105 & 36.4547 & 35.2064 & 43.6964 \\
\hline Early & & 0.0000 & 0.2974 & 0.0000 & 1.0000 \\
\hline Rounds & & 1.0000 & 2.5485 & 2.0000 & 3.0000 \\
\hline Capital & US\$ million & 6.3900 & 32.2830 & 17.8800 & 42.5050 \\
\hline Time & Years & 0.4712 & 1.0227 & 0.8356 & 1.3425 \\
\hline Syndication & & 2.0000 & 4.0035 & 3.0000 & 6.0000 \\
\hline Market return & $\%$ & 4.8532 & 18.0366 & 16.7482 & 32.5921 \\
\hline IPO return & $\%$ & 11.6000 & 31.3233 & 18.5000 & 39.9000 \\
\hline Number IPOs & & 21.0000 & 40.0217 & 39.0000 & 56.0000 \\
\hline \multicolumn{6}{|c|}{ Panel B: Initial public offering financing rounds } \\
\hline$p$ & & 0.1792 & 0.2873 & 0.2756 & 0.3711 \\
\hline$q$ & & 0.2435 & 0.3942 & 0.3576 & 0.5127 \\
\hline$u$ & & 1.9251 & 4.9356 & 2.9704 & 5.0454 \\
\hline$r_{f}$ & $\%$ & 4.6996 & 5.3281 & 5.5929 & 6.0268 \\
\hline$r$ & $\%$ & 30.0105 & 33.6499 & 35.2064 & 35.2064 \\
\hline Rounds & & 2.0000 & 3.2706 & 3.0000 & 4.0000 \\
\hline Capital & US\$ million & 35.8600 & 71.7069 & 55.2000 & 90.0000 \\
\hline Time & Years & 0.4384 & 1.3458 & 0.9123 & 1.7781 \\
\hline Offer price & US\$ & 10.0000 & 13.0331 & 12.5000 & 16.0000 \\
\hline Change price & $\%$ & -11.1111 & 5.8178 & 5.6349 & 20.0000 \\
\hline Syndication & & 2.0000 & 4.5079 & 4.0000 & 6.0000 \\
\hline Market return & $\%$ & 5.0015 & 20.0357 & 17.6076 & 35.6307 \\
\hline IPO return & $\%$ & 11.9400 & 32.2658 & 18.7000 & 41.4000 \\
\hline Number IPOs & & 2.0000 & 4.5079 & 4.0000 & 6.0000 \\
\hline
\end{tabular}


Table 5: In-sample model performance

This table presents the in-sample model performance to explain the risk-neutral probabilities of 3,926 venture capital financing rounds (Panel A) and 1,360 initial public offering financing rounds (Panel B) between January, 1986 and December, 2008. The estimation models are linear regression (Linear) from Eq. (5), multilayer-perceptron neural networks (MLP) from Eq. (8), and cascade neural networks (Cascade) from Eq. (11). The in-sample diagnostics include the Jarque-Bera (JB) test of normality of residuals, the Lee-White-Granger (LWG) test of nonlinearity, the Hannan-Quinn information criterion (HQIFC), the sum of squared (SSE), the mean squared error (MSE), and the coefficient of determination (R-squared).

\begin{tabular}{|c|c|c|c|}
\hline & Linear & MLP & Cascade \\
\hline \multicolumn{4}{|c|}{ Panel A: Venture capital financing rounds } \\
\hline JB [a] & 0.0000 & 0.0000 & 0.0000 \\
\hline LWG $[\mathrm{b}]$ & 1000 & - & - \\
\hline HQIFC & -3.9425 & -3.9909 & -3.9922 \\
\hline SSE & 66.6972 & 62.2336 & 60.3471 \\
\hline MSE & 0.0193 & 0.0181 & 0.0180 \\
\hline R-squared & 0.2007 & 0.2545 & 0.2768 \\
\hline \multicolumn{4}{|c|}{ Panel B: Initial publicoffering financing rounds } \\
\hline JB [a] & 0.0000 & 0.0000 & 0.0000 \\
\hline LWG [b] & 302 & - & - \\
\hline HQIFC & -4.0720 & -4.0645 & -4.0730 \\
\hline $\mathrm{SSE}$ & 21.2097 & 21.3544 & 20.9813 \\
\hline MSE & 0.0169 & 0.0169 & 0.0168 \\
\hline R-squared & 0.1936 & 0.1881 & 0.2027 \\
\hline
\end{tabular}

[a] Denotes probability value.

[b] The number of trials for neglected nonlinearity out of 1000 experiments. 
Table 6: Variable significance testing

This table presents the statistical significance of the independent variables to explain the risk-neutral success probabilities. The sample consists of 3,926 venture capital financing rounds (Panel A) and 1,360 initial public offering financing rounds (Panel B) between January, 1986 and December, 2008. The estimation models are linear regression (Linear) from Eq. (5), multilayer-perceptron neural networks (MLP) from Eq. (8), and cascade neural networks (Cascade) from Eq. (11).

\begin{tabular}{|c|c|c|c|}
\hline & Linear & MLP & Cascade \\
\hline \multicolumn{4}{|c|}{ Panel A: Venture capital financing rounds } \\
\hline & t-statistic [a] & t-statistic [b] & t-statistic [b] \\
\hline Early & $-10.7017^{* * *}$ & $-129.6933^{* * *}$ & $-77.3485^{* * *}$ \\
\hline Rounds & $8.7313^{* * *}$ & $-88.2585^{* * *}$ & $-67.2773^{* * *}$ \\
\hline Capital & $-20.0496 * * *$ & $-587.5666^{* * *}$ & $-503.9714^{* * *}$ \\
\hline Time & 1.0363 & $-2.1890 * *$ & $-6.0487^{* * *}$ \\
\hline Syndication & 1.0811 & $-25.0509 * * *$ & $-9.6924^{* * *}$ \\
\hline Market return & $-4.4288^{* * *}$ & $-46.2289^{* * *}$ & $-4.4521^{* * *}$ \\
\hline IPO $r$ & $-3.0100 * * *$ & - & - \\
\hline nber IPOs & $-6.0129 * * *$ & $-35.9740 * * *$ & $-13.8847^{* * *}$ \\
\hline \multicolumn{4}{|c|}{ Panel B: Initial public offering financing rounds } \\
\hline & t-statistic [a] & t-statistic [b] & t-statistic [b] \\
\hline & $5.5058 * * *$ & $-112.4975^{* * *}$ & $-53.4745^{* * *}$ \\
\hline Capital & -0.8339 & - & - \\
\hline Time & 0.2942 & 13.8858 & $-28.5888^{* * *}$ \\
\hline Syndication & 0.0296 & - & - \\
\hline Offer price & $-3.0675^{* * *}$ & $-75.2167 * * *$ & $-49.0918^{* * *}$ \\
\hline Change price & $-6.2943 * * *$ & $-81.6764^{* * *}$ & $-61.8299 * * *$ \\
\hline Market return & $-5.1676^{* * *}$ & $-110.9548^{* * *}$ & $-58.4517^{* * *}$ \\
\hline IPO return & $1.9479 * *$ & - & - \\
\hline Number IPOs & -0.0520 & - & - \\
\hline
\end{tabular}

[a] t-statistics are based on partial derivatives of the dependent and the independent variables, $\partial y / \partial x_{i}$. The t-statistics are White's (1980) heteroskedasticity consistent errors and covariances. The values of the regression intercepts are not reported.

[b] Testing that the independent variable $x_{i}$ is statistically significant is based on H0: $\operatorname{HQIFC}\left(x_{i}\right)=\operatorname{HQIFC}$ against the alternative $\operatorname{HA}: \operatorname{HQIFC}\left(x_{i}\right)<\operatorname{HQIFC}$ and involves a t-test. The one-tailed p-values are calculated from empirical density functions and bootstrap analysis.

***, ${ }^{* *}$ denotes $1 \%$ and $5 \%$ significance levels, respectively. 
Table 7: Out-of-sample tests on the estimation accuracy of risk

This table presents the out-of-sample estimation errors and comparison between the risk-neutral and the risk-adjusted framework. The risk-neutral success probability $p$ and the risk-adjusted success probability $q$ are the proxy measures for risk as defined in Table 3. The out-of-sample observations are randomly selected from 3,926 venture capital financing rounds (Panel A) and 1,360 initial public offering financing rounds (Panel B) between January, 1986 and December, 2008. The estimation models are linear regression (Linear) from Eq. (5), multilayer perceptron neural networks (MLP) from Eq. (8), and cascade neural networks (Cascade) from Eq. (11). BR is the ratio of the 0.632 bootstrap (Eq. 16) estimates in relation to the estimates of the linear regression models. SSE is the sum of squared error. MSE is the mean squared error. RMSQ is the root mean squared error. $R$ is the correlation coefficient between the ex ante and the ex post probabilities.

\begin{tabular}{lccc|ccc}
\hline \multicolumn{7}{c}{ Panel A: Venture capital financing rounds } \\
\hline & \multicolumn{2}{c}{ Risk-neutral framework } & \multicolumn{2}{c}{ Risk-adjusted framework } \\
\cline { 2 - 7 } BR & Linear & MLP & Cascade & Linear & MLP & Cascade \\
\cline { 2 - 7 } SSE & - & 0.9406 & 0.9387 & - & 0.9631 & 0.9620 \\
MSE & 0.0197 & 0.0183 & 0.0182 & 0.0407 & 0.0393 & 0.0390 \\
RMSQ & 0.1404 & 0.1352 & 0.1350 & 0.2018 & 0.1983 & 0.1975 \\
R & 0.4664 & 0.5290 & 0.5256 & 0.3989 & 0.4304 & 0.4377 \\
\hline \multicolumn{7}{c}{ Panel B: Initial public offering } \\
\hline \multicolumn{7}{c}{ financing rounds } \\
BR & 23.2678 & 23.1834 & 42.6531 & 41.1782 & 40.8564 \\
SSE & 7.5474 & 6.9017 & 6.8030 & 13.9767 & 13.9124 & 13.8335 \\
MSE & 0.0160 & 0.0153 & 0.0151 & 0.0339 & 0.0330 & 0.0336 \\
RMSQ & 0.1265 & 0.1238 & 0.1230 & 0.1842 & 0.1838 & 0.1832 \\
R & 0.4233 & 0.4976 & 0.5057 & 0.4427 & 0.4463 & 0.4521 \\
\hline
\end{tabular}


Table 8: Out-of-sample tests on the estimation accuracy of return This table presents the out-of-sample estimation errors and comparison between the risk-neutral and the risk-adjusted framework. The upmovement in firm value $u$ is the proxy measure for return as defined in Table 3. The out-of-sample observations are randomly selected from 3,926 venture capital financing rounds (Panel A) and 1,360 initial public offering financing rounds (Panel B) between January, 1986 and December, 2008. The estimation models are linear regression (Linear) from Eq. (5), multilayer perceptron neural networks (MLP) from Eq. (8), and cascade neural networks (Cascade) from Eq. (11). BR is the ratio of the 0.632 bootstrap (Eq. 16) estimates in relation to the estimates of the linear regression models. SSE is the sum of squared error. MSE is the mean squared error. RMSQ is the root mean squared error. $\mathrm{R}$ is the correlation coefficient between the ex ante and the ex post up-movement in firm value.

\begin{tabular}{|c|c|c|c|c|c|c|}
\hline \multicolumn{7}{|c|}{ Panel A: Venture capital financing rounds } \\
\hline & \multicolumn{3}{|c|}{ Risk-neutral framework } & \multicolumn{3}{|c|}{ Risk-adjusted framework } \\
\hline & Linear & MLP & Cascade & Linear & MLP & Cascade \\
\hline SSE & 65480 & 60166 & 60009 & 89874 & 68871 & 68434 \\
\hline MSE & 18.9413 & 17.4042 & 17.3588 & 31.7351 & 24.3190 & 24.1645 \\
\hline MAE & 1.8254 & 1.7217 & 1.7094 & 2.0039 & 1.8466 & 1.8538 \\
\hline $\mathrm{R}$ & 0.2546 & 0.4387 & 0.3776 & 0.1388 & 0.3973 & 0.3749 \\
\hline \multicolumn{7}{|c|}{ Panel B: Initial public offering financing rounds } \\
\hline & \multicolumn{3}{|c|}{ Risk-neutral framework } & \multicolumn{3}{|c|}{ Risk-adjusted framework } \\
\hline & Linear & MLP & Cascade & Linear & MLP & Cascade \\
\hline SSE & 124899 & 126475 & 122902 & 780057 & 260477 & 255999 \\
\hline MSE & 98.8126 & 100.0594 & 97.2327 & 683.0630 & 228.0883 & 224.1671 \\
\hline MAE & 2.7114 & 2.7162 & 2.6696 & 4.0774 & 3.1903 & 3.1668 \\
\hline $\mathrm{R}$ & 0.3439 & 0.3422 & 0.3686 & 0.0770 & 0.6192 & 0.6260 \\
\hline
\end{tabular}

